\title{
EDITORIAL
}

\section{How Positive Ways can Boom Sustainable Development}

\section{Chia-Huei Wu*}

Institute of Service Industries and Management, Minghsin University of Science and Technology, Hsinchu 304, Taiwan

\begin{tabular}{l}
\hline ARTICLE INFO \\
\hline Article history \\
Received: 23 June 2020 \\
Accepted: 23 June 2020 \\
Published Online: 30 June 2020 \\
\hline Keywords: \\
Sustainable development \\
Sustainable economic \\
Social development \\
Sustainability
\end{tabular}

\section{Introduction}

$\mathrm{S}$ ustainable economic and social development are significant, and macro-management and public policies are double-edged swords for sustainability. For example, On the one hand, macro-management and public policies have positive effects on resource protection ${ }^{[6]}$, quality enhancement ${ }^{[2]}$, and successes of social movements ${ }^{[4]}$. On the other hand, inappropriate management ways and policies are more likely to trigger crises and risks of wars ${ }^{[3]}$.

Moreover, policies sometimes bring out positive impacts on the economy but negative effects on the environment, so sustainable development demands the balance between economic growth and environmental protection. In the case of land-use transitions, although there is a challenge between urbanization and environmental protection, such as priority to the economy ${ }^{[1]}$, related managerial and political measures can regulate land-use activities to some extent.

\begin{abstract}
This editorial introduces the issue of Macro Management \& Public Policies, which focuses on how positive ways can boom sustainable development, how inappropriate policies inhibit the development, or even cause intense problems such as risks of wars. The outcomes show some implicaitons, first of all, management and policies has dual effects. On the one hand, effective management and policies contribute to resource protection, quality enhancement, and successes of social movements. On the other hand, political unfairness may cause crisis in international society. Moreover, law priority has comprehensive influence on development. Keeping economic and social development, authorities should balance economic growth and environmental protection, keep consistency between regulations and implementation, and ensure effective supervision.
\end{abstract}

The main purpose of this issue is, firstly, to enrich knowledge on sustainable development within macro management and public policy. In addition, it can help policy-makers aware of the dual effects of management and policies at the macro level, promoting the positive effects and reducing the negative impacts.

\section{Overview of the Articles in this Issue}

This issue of Macro Management \& Public Policies incorporates five important articles, divided into two parts: the single effect of management or public policies, and the comprehensive effects based on the cases of the planification law in China.

First of all, in terms of positive effects, Zhang and Zhang ${ }^{[6]}$ build a model involving marine economic development and promote the legalization and institutionalization of marine resource protection. The legal system can help adjust relations between marine resource protection

*Corresponding Author:

Chia-Huei Wu,

Institute of Service Industries and Management, Minghsin University of Science and Technology, Hsinchu 304, Taiwan;

Email: chiahuei530@gmail.com 
and social production. and provide a legal guarantee for marine resources.

$\mathrm{Xu}^{[2]}$ discusses the relationships between quality and efficiency in the enterprise, and ways on how to realize high quality. The paper reveals that there are various means for corporations to achieve quality goals. For example, enterprises can recruit high-quality employees, understand equipment and products of firms through communicating with workers, improve the quality of equipment and products by equipment promotion from equipment personnel, improve moulds, and quickly respond to demands from markets.

As for sustainable movement and its success factors, Sun ${ }^{[4]}$ explores the change of positions of Social Movement Organizations (SMOs) from the past to the digital age, in the light of the successful example of 15-M Movement and the comparison between collective action and connective action. The author finds that SMOs play a significant role in gathering individuals within common interests; social media has become popular in movements, changing people's lives; the 15-M Movement has engaged over 60 countries by excluding brick and mortar organizations, avoiding the "free ride" problem and contributing to its success.

In terms of negative effects, by investigating the cause of defeats of the Versailles System, Jiang ${ }^{[3]}$ uncovers the unfair and passive outcomes of the agreements, Treaty of Versailles, directly triggering the increase of the Nazi. The Versailles System, in nature, was that allied nations demanded large numbers of reparations and punishment on defeated states, and recovered their powers by utilizing peace as an excuse after World War I. For example, policies of appeasement revealed that peace was at the expense of small countries.

Furthermore, Zhang ${ }^{[1]}$ reveals the dual influence of laws, improving urbanization but causing environmental degradation, based on arguing whether the law of plan- ification in China involves environment protection. The author, firstly, at macro-levels, explores the reform of the land ownership, and then finds that the state delegated local governments to manage the use of land and that environment degraded as the processes of urbanization. Besides, at micro-levels, the author studies the regulations of planification, procedures, and formalities. The results illustrate the need for coherence, accessibility, and understanding of laws, rapid urbanization resulting in a reconfiguration of the urban space, and governance facing challenges of the paradox of urbanization and environmental degradation. Finally, problems should be paid attention to. For example, current laws on planification are preferred to economic growth rather than environmental protection; the environmental focus is still very limited due to the lack of effective supervision.

\section{References}

[1] Li Zhang. A Discussion for the protection of the environnement in the law of planification in China. Journal of Macro Management \& Public Policies, 2020.

[2] Run Xu. The relationship between quality and efficiency in business management. Journal of Macro Management \& Public Policies, 2020.

[3] Yiran Jiang. The Major Cause of the Collapse of the Versailles System. Journal of Macro Management \& Public Policies, 2020.

[4] Yutong Sun. The Existence of Social Movement Organization(SMO) \&Comparison of Collective and Connective Action in the Digital Era: an Analysis of 15-M Movement in Spain. Journal of Macro Management \& Public Policies, 2020.

[5] Zhenan Zhang, Lijuan Zhang. An Analysis of the Legal System for the Protection of Marine Resources in China. Journal of Macro Management \& Public Policies, 2020. 